\title{
The Effect of Adapted Basketball Exercises on the Development of Non-Oral Communication Skills of Autistic Children
}

\author{
Hulusi Alp ${ }^{1}$, Sinan Akın ${ }^{2}$ \\ ${ }^{1}$ Faculty of Sport Sciences, Süleyman Demirel University, Isparta, Turkey \\ ${ }^{2}$ Faculty of Sport Sciences, Kütahya Dumlupınar University, Kütahya, Turkey \\ Correspondence: Hulusi Alp, Faculty of Sport Sciences, Süleyman Demirel University, Isparta, Turkey.
}

Received: August 7, 2019

Accepted: September 4, 2019

Online Published: September 9, 2019

doi:10.11114/jets.v7i10.4435

URL: https://doi.org/10.11114/jets.v7i10.4435

\begin{abstract}
The aim of this study was to determine the effect of adapted basketball exercises on the development of nonverbal communication skills of autistic children. Among the single-subject research models, multiple-polling inter-polling behavior was used. The population of the study consists of children with mild autism spectrum disorder in the special education center in which autistic children are educated in Isparta. The sample of the study was determined by using simple random sampling method for two (2) mildly autistic children of ten (10) years. Written consent was obtained from the parents for the selected children to participate in the study. The aim of the study is to teach selected children the skills of non-verbal communication, to the other person, to shake hands and to shake hands with the other person. The study lasted a total of seventeen (17) weeks, one week of observation and sixteen weeks of application. The same program was applied to both children during the study. The content of the program consists of teaching basic technical skills specific to basketball. These skills include ball holding, right and left hand bouncing, right and left hand dribbling, chest pass, bounce pass, overhead pass and smash techniques. The skills were adapted to the readiness levels of both children. In order to record the data, video camera, entry level data recording form and teaching process data recording forms were used. The data obtained at the end of the application were analyzed by showing on the graph. Since the number of participants was two (2), the data obtained during the seventeen (17) week period were converted to point points in accordance with the scale protocol and converted to line graphs to reveal the change. When the findings of the study were evaluated, it was seen that there were positive changes in the development of non-verbal communication skills of autistic children who extended their hands, squeezed their hands and shook hands with the other person.
\end{abstract}

Keywords: autism, communication skills, basketball

\section{Introduction}

Autism spectrum disorder is a disorder characterized by stereotypes and verbal and non-verbal communication, play and social relations that occur during the first three years of life due to various developmental causes (Korkmaz, 2000; Diken, 2014). In other words, autism is the situation where an individual moves away from the realities of the outside world and creates his own inner World (Öztürk, 1997). The exact causes of autism are not known. However, while some researchers stress that there are functional disorders in the brain regions where the stimuli from the environment are processed, other researchers argue that they cause imbalances in the secretion of chemical substances in the body (Ekiz et al., 2015). People have to communicate with each other in order to meet their needs and desires. Communication is the process of transmitting any message in any form. The most common forms of communication are speech, writing, painting and gestures (Poulson, 2009). Children with disabilities also want to establish and maintain social relationships and communication with other people (Göksu, 2004). The emotional development of children with autism is similar to that of children with normal development. The only difference is the delay in development. One-year-old child's crying behind his mother may occur in a child with autism at the age of four or five (Persson, 2002). Failure to communicate with individuals in the environment is a feature of autism. In autistic children, education should start with communication skills training. Because, proper communication skills are necessary for education (Okan \& Okan, 2006). According to Sucuoglu et al., (1998), communication skills are also insufficient in children with autism. This deficiency affects verbal and nonverbal communication skills of autistic children. Non-verbal communication: lack of language development is the first sign of autism. Some of the movements of babies, such as smile and waving, are the beginning of verbal communication. It is seen that babies we normally accept laugh at sounds 
and follow moving objects, while autistic children are only tickled and laughed when they are thrown into the air (Okan \& Okan, 2006; Kulaksizoğlu, 2003). The movement of the individual is important for both himself and his environment. Movement, just like language, is a means by which people communicate with their environment, express themselves and realize their lives (Özbar, 2009). Education is the process of changing people and related societies (Çamliyer, 1994). When necessary and appropriate educational arrangements are made, many children with autism get rid of this problem to a great extent and can continue the rest of their lives by fusing with their normally developing peers and society (Güleç at al., 2009). It is observed that teachers use different teaching methods and techniques while teaching communication skills to autistic children (Kurcaali-iftar, 2003). Communication, education and verbal behavior method is started to work on expressive language skills without waiting for the receiving language skills to reach a certain level. In this method, function is always considered more important than form. Therefore, during the teaching of requesting, which is the first step, it is ensured that the child expresses and reaches the request in a speech, gesture, sign or any other way in the context of a genuine request. The prerequisite of both communication skills and academic and social skills is the ability to perform the given commands. For every autistic child, it should first focus on this issue (Sucuoglu et al., 1998). It has shown that behaviors gained in psychosocial areas are transferred to similar and necessary situations in daily life through sports activities (Çamliyer, 2011). In addition to being a team game, basketball also has an individual goal. As a result of routine movements, throwing the ball into a circle, leaping, accelerating movements and using the power of the arm with the right command is to throw the ball into the circle. It helps individuals with autism to engage in activities outside their range of motion, and at the same time helps them achieve a goal for the moment. It may also be able to teach autistic children with basketball skills such as waiting for their turn, listening and following instructions.

The aim of this study is to investigate the effect of adapted basketball exercises on the development of nonverbal communication skills of autistic children.

\section{Method}

\subsection{Research Model and Purpose}

The aim of the study was to determine the effect of adapted basketball exercises on the development of nonverbal communication skills of autistic children. Among the single-subject research models, the multiple-polling model was used among the polling-stage behaviors. The multiple start level model allows simultaneous analysis of multiple dependent variables. A researcher can experimentally test the effect of an intervention (Sarı \& Öğülmüş, 2015).

\subsection{Research Group}

The population of the study consists of children with mild autism spectrum disorder in the special education center where autistic children are educated in Isparta. The sample of the study was determined by using simple random sampling method for two (2) mildly autistic children of ten (10) years. Written consent was obtained from the parents for the selected children to participate in the study.

\subsection{Data Collection Tools}

Event recording from observation based recording systems is used as data collection tool. Event recording is the observation recording process that reflects the number of occurrences of a behavior in the most direct and accurate way (Vuran \& Ünlü, 2015).

\subsection{Statistical Analysis of Data}

At the end of the study, the obtained data were analyzed by showing on the graph. Since the number of participants was two (2), the data obtained during the sixteen (16) week period were converted to point points in accordance with the scale protocol and converted to line graphs to reveal the change occurring. Line graphs are often used to serialize data generated during training or intervention. Numbers 0 to 2 were used to express the frequency of behavior. $0=$ Never doing. 1 = Occasionally. 2 = Always doing.

This allows for ongoing monitoring of behavior and assessment of training or intervention (Sar1 \& Sar1, 2015).

\subsection{Selection of Targeted Communication Skills and Working Time}

The aim of the study is to teach selected children the skills of nonverbal communication, extends his hand to the other person, shakes hands with the other person and makes handshake with the other person, their behavior. The behaviors aimed to be taught were determined as a result of the information gathered from the psychologists and classroom teachers and observations. The study lasted a total of seventeen (17) weeks, one week of observation and sixteen weeks of application. The same education program was applied to both children during the study. The content of the program consists of teaching basic technical skills specific to basketball. These skills include ball holding, right and left hand bouncing, right and left hand dribbling, chest pass, bounce pass, overhead pass and smash throwing. Basketball basic skills were prepared and applied according to the readiness levels of both children. 


\subsection{Information About of Akın}

In order to gather information about Akın, the researcher was interviewed by the child's family and the school's psychologist. The child was diagnosed with mild autism spectrum disorder by a specialist psychiatrist when he was three years old. It was stated by the psychologist and the family of the child that the child did not perform social skills such as making eye contact, looking at his name, greeting, starting a conversation, maintaining, following the instructions and following the rules. In addition, it was observed that the child did not perform social skills as a result of the three-day observation conducted by an expert researcher in children's schools.

\subsection{Information About of Mine}

In order to gather information about Akın, the researcher was interviewed by the child's family and the school's psychologist. The child was diagnosed with mild autism spectrum disorder by a specialist psychiatrist when he was two years old. It was stated by the psychologist and the family of the child that the child did not perform social skills such as making eye contact, looking at his name, starting a conversation, maintaining, following the instructions and following the rules. In addition, it was observed that the child did not perform social skills as a result of the three-day observation conducted by an expert researcher in children's schools.

\section{Findings}

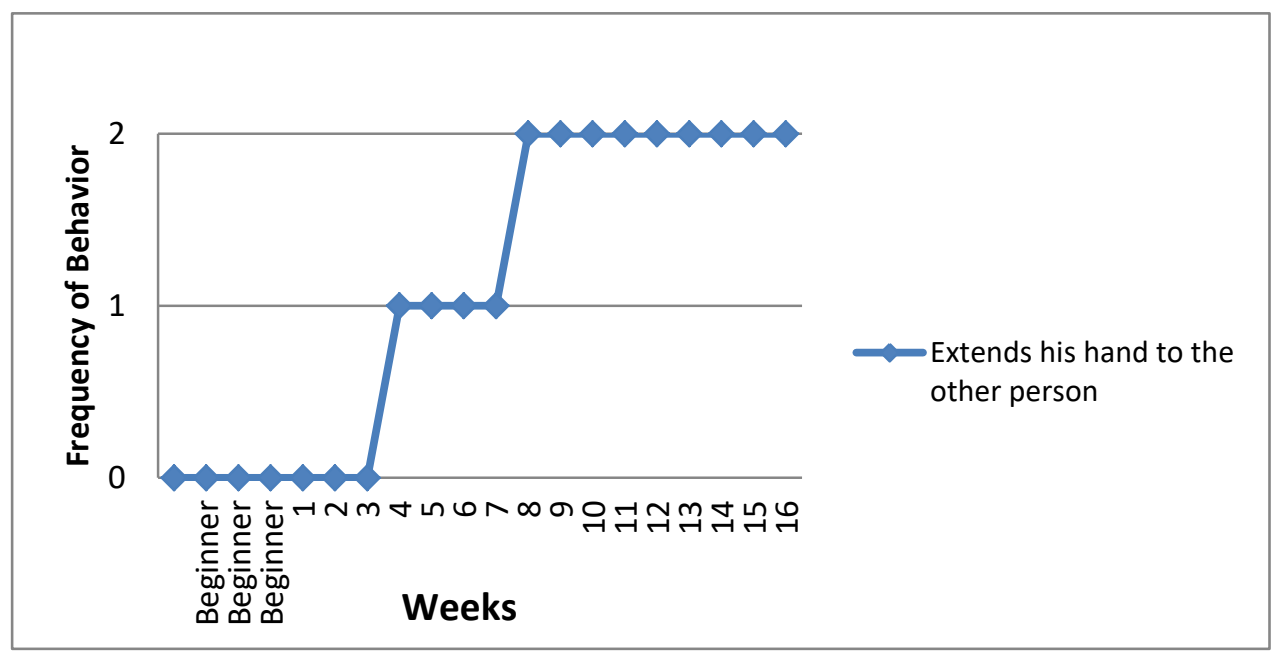

Figure 1. Akın's "extends his hand to the other person" graph showing the frequency of communication skills

Looking at Figure 1, it is seen that at beginner level and adapted basketball exercises first three (3) weeks after the start, extends his hand to the other person, there is no change in behavior. Between the 3rd and 16th weeks of the study, it is seen that there is a positive change in behavior.

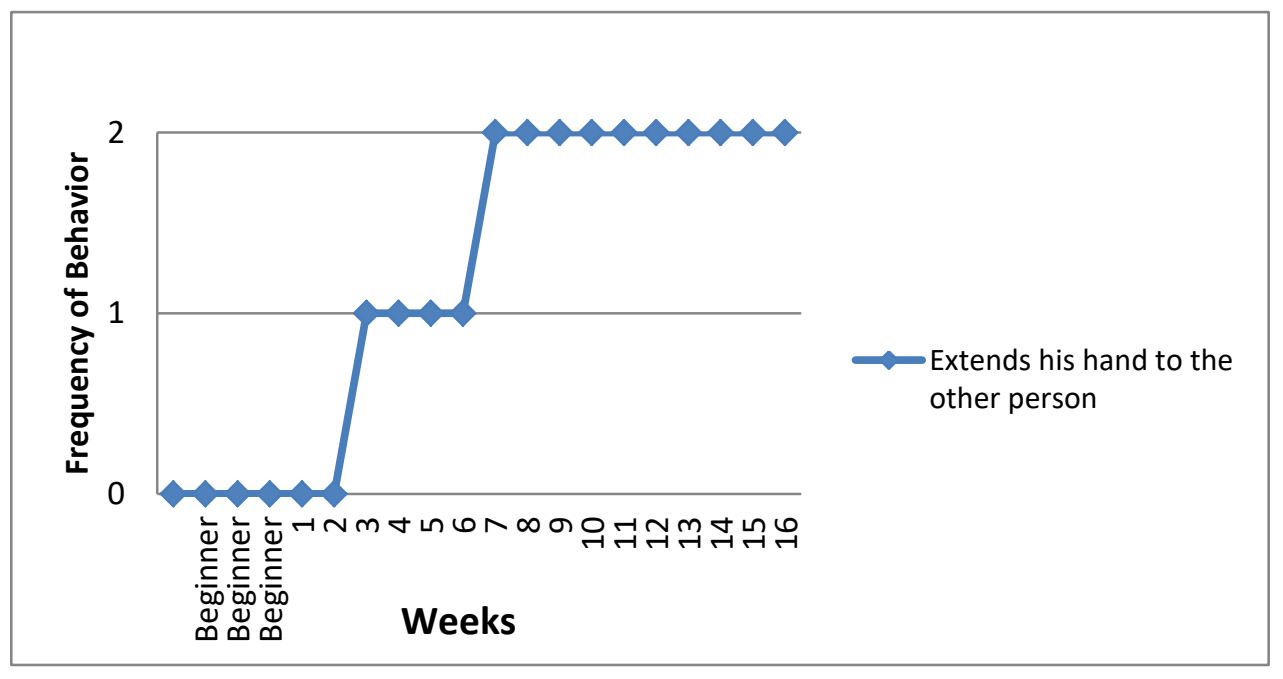

Figure 2. Mine's "extends his hand to the other person" graph showing the frequency of communication skills 
Looking at Figure 2, it is seen that at beginner level and adapted basketball exercises first two (2) weeks after the start, extends his hand to the other person, there is no change in behavior. Between the 2rd and 16th weeks of the study, it is seen that there is a positive change in behavior.

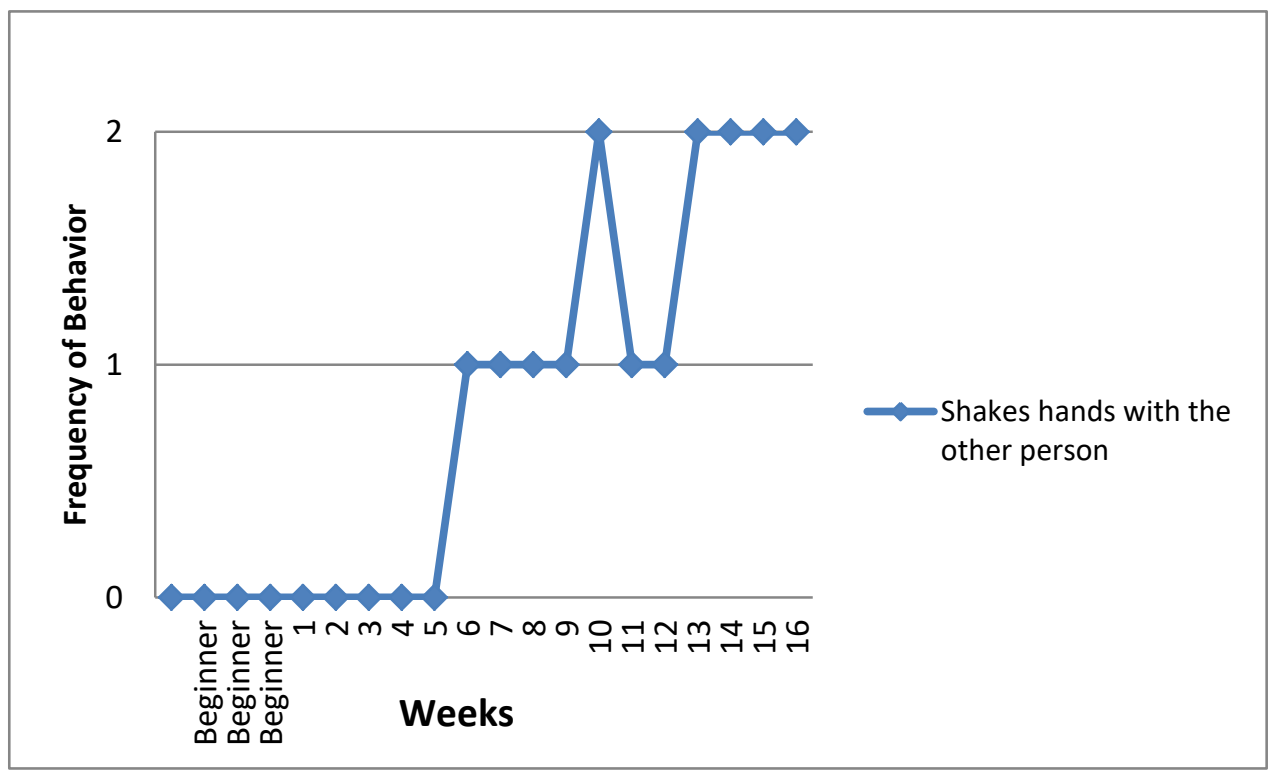

Figure 3. Akın's "shakes hands with the other person" graph showing the frequency of communication skills

Looking at Figure 3, it is seen that at beginner level and adapted basketball exercises first four (5) weeks after the start, shakes hands with the other person, there is no change in behavior. Between the 5rd and 16th weeks of the study, it is seen that there is a positive change in behavior.

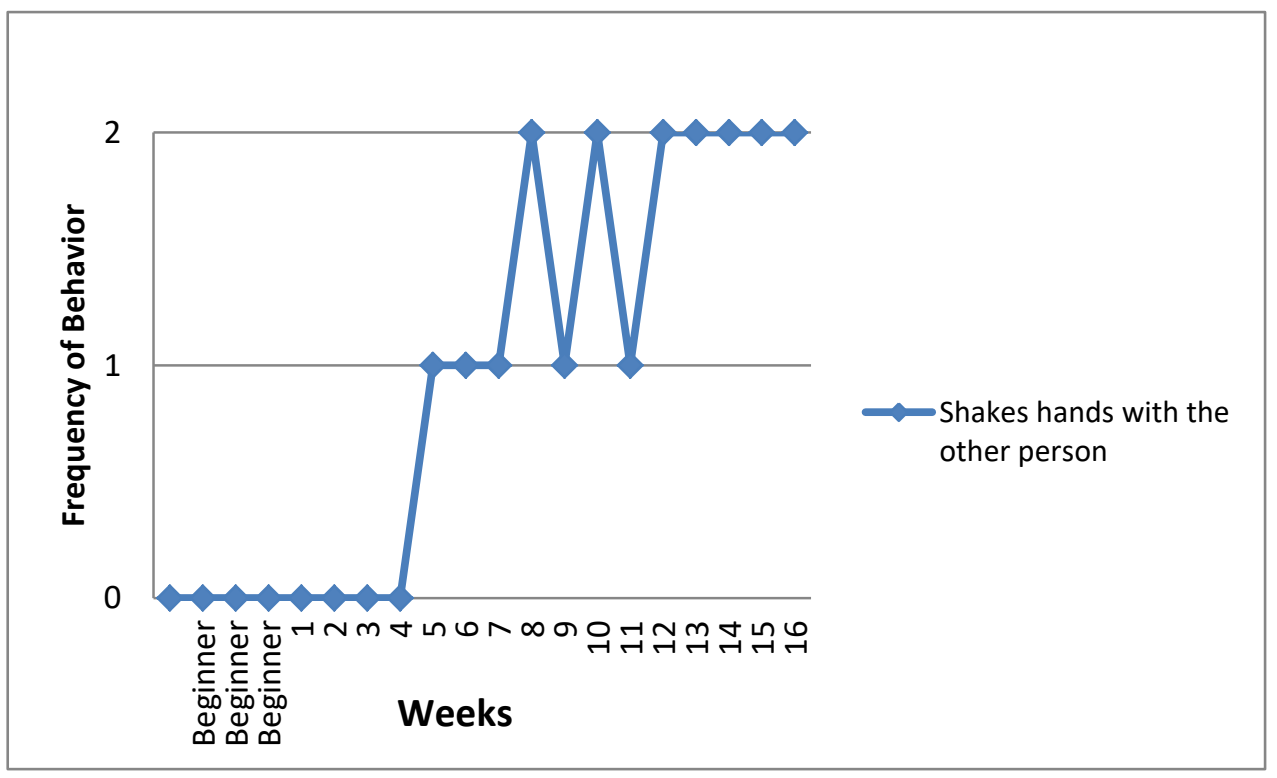

Figure 4. Mine's "shakes hands with the other person" graph showing the frequency of communication skills

Looking at Figure 4, it is seen that at beginner level and adapted basketball exercises first four (4) weeks after the start, shakes hands with the other person, there is no change in behavior. Between the 3rd and 16th weeks of the study, it is seen that there is a positive change in behavior. 


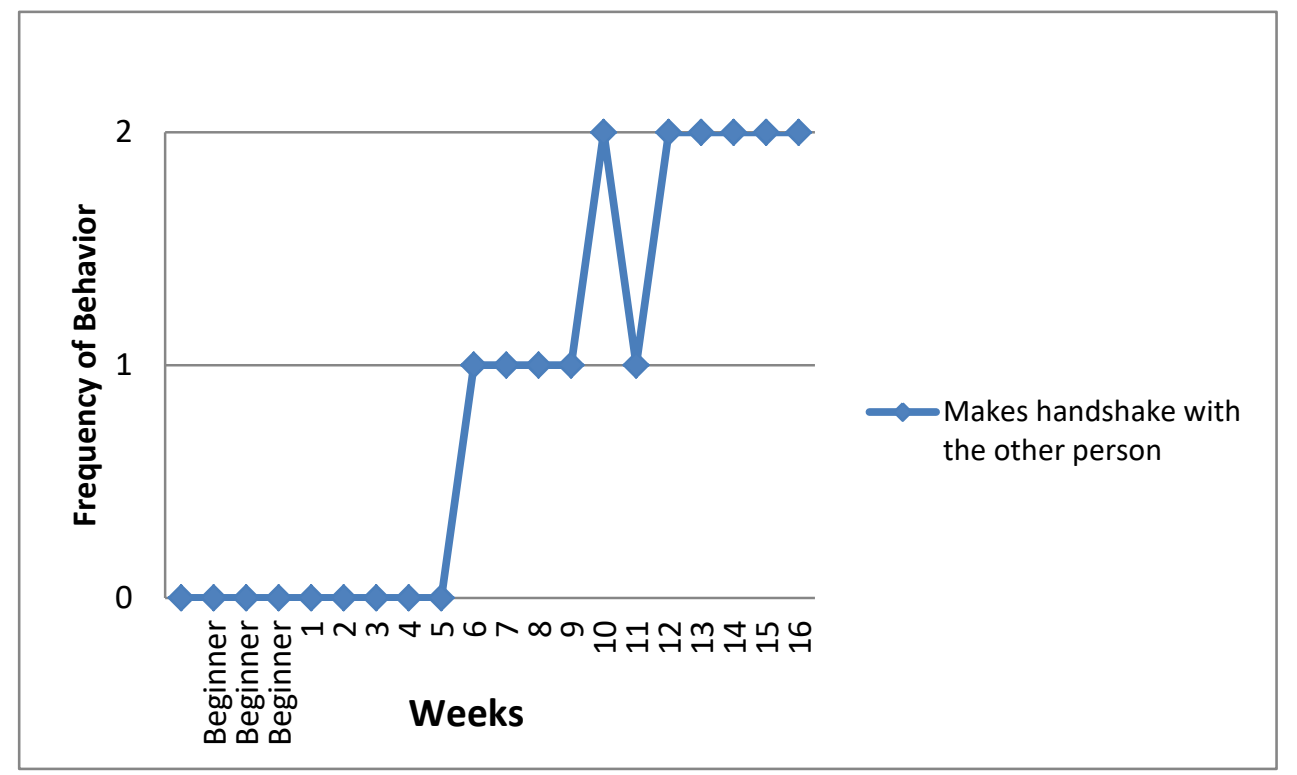

Figure 5. Akın's "makes handshake with the other person" graph showing the frequency of communication skills

Looking at Figure 5, it is seen that at beginner level and adapted basketball exercises first five (5) weeks after the start, makes handshake with the other person, there is no change in behavior. Between the 5rd and 16th weeks of the study, it is seen that there is a positive change in behavior.

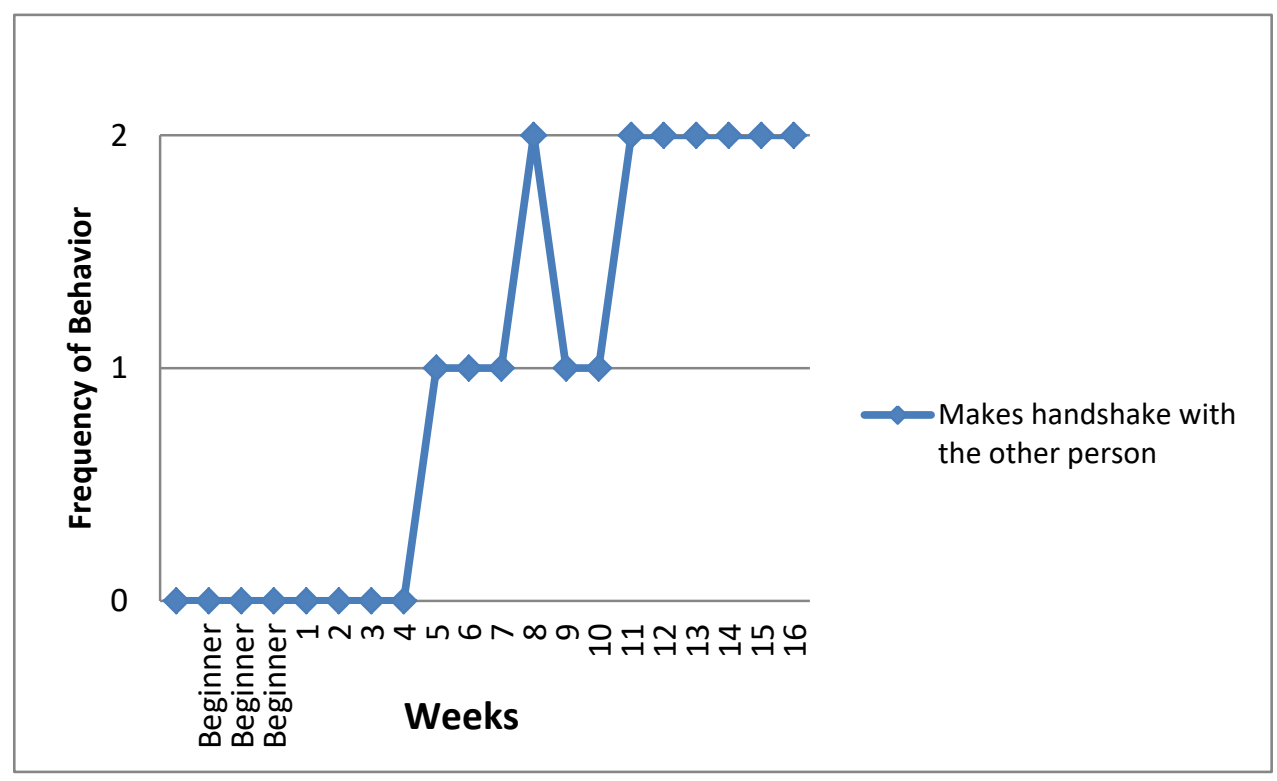

Figure 6. Mine's "makes handshake with the other person" graph showing the frequency of communication skills

Looking at Figure 6, it is seen that at beginner level and adapted basketball exercises first four (4) weeks after the start, makes handshake with the other person, there is no change in behavior. Between the 5rd and 16th weeks of the study, it is seen that there is a positive change in behavior.

\section{Discussion and Conclusion}

The aim of this study was to determine the effect of adapted basketball exercises on the development of nonverbal communication skills of autistic children. The findings obtained from the analyzes were interpreted in this section with the support of the literature.

According to the results in Figure 1, Akın' s, extends his hand to the other person, before the start of the study, he never 
does his behavior. After the study has started, there is a positive change in the frequency of the same behavior. It can be said that adapted basketball exercise program has an effect on Akın's behavior change.

According to the results in Figure 2, Mine's, extends his hand to the other person, before the start of the study, he never does his behavior. After the study has started, there is a positive change in the frequency of the same behavior. It can be said that adapted basketball exercise program has an effect on Mine's behavior change.

According to the results in Figure 4, Akın's, shakes hands with the other person, before the start of the study, he never does his behavior. After the study has started, there is a positive change in the frequency of the same behavior. It can be said that adapted basketball exercise program has an effect on Akın's behavior change.

According to the results in Figure 4, Mine's, shakes hands with the other person, before the start of the study, he never does his behavior. After the study has started, there is a positive change in the frequency of the same behavior. It can be said that adapted basketball exercise program has an effect on Mine's behavior change.

According to the results in Figure 5, Akın's, makes handshake with the other person, before the start of the study, he never does his behavior. After the study has started, there is a positive change in the frequency of the same behavior. It can be said that adapted basketball exercise program has an effect on Akın's behavior change.

According to the results in Figure 6, Mine's, makes handshake with the other person, before the start of the study, he never does his behavior. After the study has started, there is a positive change in the frequency of the same behavior. It can be said that adapted basketball exercise program has an effect on Mine's behavior change.

The results of the research, which showed that there are positive changes in the nonverbal communication skills of the autistic children, are similar to the results of some studies in the literature.

Adapted sport has a supportive function not only physically but also spiritually and socially (Yanardağ, 2017). Lancioni \& O'Reilly (1998) in his study, physical exercise not only improves the physical condition but also reduces the maladaptive behavioural patterns of people with autisn spectrum disorder. María et al. (2017), found that the effects of a program of sport schools on development of social and psychomotor skills of people with autistic spectrum disorders, concluded that autistic children contribute to the development of social skills. Nijafabadi et al. (2015), sports, play and active recreation for kids's training can be considered as a therapeutic option not only for motor enhancement but also for improving social skills in children with autism spectrum disorder. According to Pan (2010), indicated that the 10-week water exercise swimming program improved the child's aquatic skills and social behaviors after the intervention, suggesting that the inclusion of physical activity treatment components targeting social skills could be made. Alexander et al. (2011), fourteen-week, study on the development of the social skills of young adult private olympic athletes, was found to develop social skills of autistic children. Bahrami et al., (2016) concluded that teaching karate techniques to children with autism spectrum led to a significant reduction in communication deficit. Bass et al., (2009) found that autistic children participating in therapeutic horseback riding activity exhibited more sensory seeking, sensory sensitivity, and social behaviors. Chu \& Pan (2012) and Brookman et al., (2003) showed that exercise studies have an important contribution to the development of communication skills of children with autism. In a study of eight children aged five to seven years with autistic spectrum disorders, it was emphasized that the adapted exercise program had positive effects on social communication and interactions (Yanardağ, Ergun \& Yılmaz, 2009). It can be said that the findings of this study with all these studies are similar.

\section{Result}

As a result, it was seen that the children with autism who participated in the study, extends his hand to the other person, shakes hands with the other person and makes handshake with the other person, positive changes in their behaviors and the program implemented was effective.

Although the same program was applied to both children, it was observed that Mine's improved better than Akın. It can be said that individual differences have an effect on this result.

\section{Suggestions}

When working, it is important to choose a time when children are not tired. Rather than performing the studies for a very long time, it would be appropriate to carry out the work in four stages of ten minutes. When talking to the child, it is effective to go down to the eye level and to speak by looking at it. It is appropriate to establish short and clear sentences when commanding the child. For example, it would be appropriate to emphasize such as look at me. It is important that there are no stimuli to distract the child from the vicinity of the study site. 


\section{References}

Alexander, M. G. F., Dummer, G. M., Smeltzer, A., \& Denton, S. J. (2011). Developing the social skills of young adult special olympics athletes. Education and Training in Autism and Developmental Disabilities, 46(2), $297-310$.

Bahrami, F., Movahedi, A., Marandi, S. M., \& Sorensen, C. (2016). The effect of karate techniques training on communication deficit of children with autism spectrum disorders. Journal of Autism and Developmental Disorders, 46(3), 978-986. https://doi.org/10.1007/s10803-015-2643-y

Bass, M. M., Duchowny, C. A., \& LIabre, M. M. (2009). The effect of therapeutic horseback riding on social functioning in children with autism. Journal of Autism and Developmental Disorders, 39(9), 1261-1267. https://doi.org/10.1007/s10803-009-0734-3

Brookman, L., Boettcher, M., Klein, E., Openden, D., Koegel, R. L., \& Koegel, L. K. (2003). Facilitating social interactions in a community summer camp setting for children with Autism. Journal of Positive Behavior Interventions, 5(4), 249-252. https://doi.org/10.1177/10983007030050040801

Çamliyer, H. (1994). Effects of movement education on perceptual development levels in educable intelligence level children. Dokuz Eylül Üniversitesi, Unpublished Doctoral Thesis, İzmir.

Çamliyer, H. (2011). Children motion training and game. Can Offset, Manisa, 2011, 116-117-136.

Chu, C. H., \& Pan, C. Y. (2012). The effect of peer-and sibling-assisted aquatic program on interaction behaviors and aquatic skills of children with autism spectrum disorders and their peers/siblings. Research in Autism Spectrum Disorders, 6(3), 1211-1223. https://doi.org/10.1016/j.rasd.2012.02.003

Diken, İ. H. (2014). Students with autism disorder. İbrahim H. Diken (Ed.), Students with special education needs and special education (pp. 410-413). Pegem Academi, 9th Edition, Ankara.

Ekiz, D., Şahin, Z. D., \& Camdan, F. (2014). An investigation of special Education teachers Communication strategies to children with autism. Turkish International Journal of Special Education and Guidance \& Counseling, 3(1), 54-67.

Göksu, İ., \& Çevik, T. (2004). Introduction to special education. Ankara.

Güleç, A. Y., Kırcaali-İftar, G., \& Uzuner, Y. (2009). Examination of home behavioral education program for children with autism (OÇİDEP) with a child. Ankara University, Faculty of Educational Sciences, Journal of Special Education, 10(1), 1-25.

Kurcaali-iftar, G. (2003). To provide communication skills to children with autistic features. Ya-pa Publications, İstanbul.

Korkmaz, B. (2000). What is Rain Kids / Autism? Dogan Bookstore, İstanbul.

Kulaksızoğlu, A. (2003). Different developing children. Epsilon Publications, İstanbul.

Lancioni, G. E., \& O’Reilly, M. F. (1998). A review of research on physical exercise with people with severe and profound developmental disabilities. Research in Developmental Disabilities, 19, 477-492.

https://doi.org/10.1016/S0891-4222(98)00019-5

María, L. J., Ricardo, M. R., María, A. C., Inmaculada, G., \& Sergio, S. (2017). Effects of a program of sport schools on development of social and psychomotor skills of people with autistic spectrum disorders: A pilot project. Journal of Education and Training Studies, 5(8), 167-177. https://doi.org/10.11114/jets.v5i8.2555

Najafabadi, M. G., Sheikh, M., Hemayattalab, R., Memari, A. H., Aderyani, M. R., \& Hafizi, S. (2018). The effect of spark on social and motor skills of children with autism. Pediatrics \& Neonatology, 59(5), $481-487$. https://doi.org/10.1016/j.pedneo.2017.12.005

Okan, K., \& Okan, N. (2006). Handicapped at home (Parent's Handbook). 1.Printing, Fora Publishing, Ankara.

Özbar, N. (2009). Football for your child. Turkey Football Federation, apple printing, 1 pth edition, İstanbul.

Öztürk, O. (1997). Mental health and disorders. HYB Publications, Ankara.

Pan, C. Y. (2010). Effects of water exercise swimming program on aquatic skills and social behaviors in children with autism spectrum disorders autism: International Journal of Research and Practice, 14(2010), 9-28. https://doi.org/10.1177/1362361309339496

Persson, S. (2002). Autistic intelligence and levels autism. 2. Printing, System Publishing, İstanbul.

Poulson, C. L. (2009). Otizmli çocuklara empati becerilerinin öğretimi. J. Appl. Behav. Anal., 42(1), 17-32. https://doi.org/10.1901/jaba.2009.42-17 
Sarı, H., \& Öğülmüş, K. (2015). Single subject research methods. Hakan Sarı (Ed.), Applied behavior analysis (s.107-123). Nobel Academic Publishing Education Consultancy, Ankara.

Sarı, H., \& Sarı, Ş. (2015). Graphing data. Hakan Sarı (Ed.), Applied behavior analysis (s.107-123). Nobel Academic Publishing Education Consultancy, Ankara.

Sucuoğlu, B., Akıncı, A., Gümüşcü, Ş., \& Pişkin,Ü. (1998). Otistik çocuklar ve eğitimleri. Ankara.

Vuran, S., \& Ünlü, E. (2015). Data collection processes. Hakan Sarı (Ed.), Applied behavior analysis (s.107-123). Nobel Academic Publishing Education Consultancy, Ankara.

Yanardağ, M. (2017). Physical education, activity, sports and adaptation. Mehmet Yanardağ \& İlker Yılmaz (Ed.), Physical education and sports for students with special needs (pp. 118-149). Pegem Academi, 1. Printing, Ankara.

Yanardağ, M., Ergun, N., \& Yılmaz, I. (2009). The effect of adapted exercise training on physical fitness in children with autism. Physiotherapy Rehabilitation, 20(1), 5-31.

\section{Copyrights}

Copyright for this article is retained by the author(s), with first publication rights granted to the journal.

This is an open-access article distributed under the terms and conditions of the Creative Commons Attribution license which permits unrestricted use, distribution, and reproduction in any medium, provided the original work is properly cited. 